\title{
ICT AND SOCIO-ECONOMIC DEVELOPMENT: \\ A UNIVERSITY'S ENGAGEMENT IN A RURAL COMMUNITY IN YOLA, NIGERIA
}

\author{
Jainaba M.L. Kah \\ American University of Nigeria, Nigeria \\ Muhammadou M.O. Kah \\ American University of Nigeria, Nigeria \& \\ American University, U.S.A.
}

\begin{abstract}
This chapter explores ICT interventions, the role of universities in socio-economic development, knowledge creation and dissemination literature before taking a look at a university intervention in ICT for development in a small rural community in Yola, Northeastern Nigeria. The African Center for ICT Innovation and Training ${ }^{1}$, an American University of Nigeria community engagement initiative is used as a case study to gauge its importance as an ICT resource center for the community and for small businesses and whether applied skills in information technology for university faculty and staff taught at the Center is leading to more productivity. The Yola and Jimeta Communities are also surveyed to find out whether the activities of the Centre and its interventions on developing ICT competencies and capacity building is helping to bridge the digital divide and empowering the community, especially women.
\end{abstract}

Keywords: ICT and Development, ICT social-economic development, ICT and women, Universities and Development

\section{Introduction}

The potential of information and communication technologies (ICT) to transform communities and economies has been touted in the literature. The expectation of ICT playing a transformational role is more evident in Africa. Africa, being the last development frontier and known as the poorest continent has begun to look at ICT as the magic bullet to solve its developmental problems. A recent 2007 publication of the Africa Capacity Building foundation asserted that the level of interest in technology solutions to critical development challenges is

\footnotetext{
${ }^{1}$ Partly funded by a seed grant from the MacArthur Foundation.
} 
high in Africa, which raises a need to accelerate the penetration and application of technology on the continent, particularly in the public sector. Technology can assist in improving efficiency and effectiveness of public sector institutions by creating the enabling environment for the continent to increase her competitiveness.

Many declarations, such as the draft Ouagadougou Declaration, recognize the importance of good governance to promote sustainable development, poverty alleviation and the enhancement of the quality of life for Africans. These documents highlight and acknowledge the importance of access to information for healthy democracies, the challenge Africa faces in building the requisite ICT skills, and the fact that e-government wields great potential for making African governments more efficient, responsive, transparent and legitimate. The roadmap for the implementation of ICT best practices addresses issues of enabling environments, infrastructure development, security, harnessing citizen information for better government services, revenue, and online citizen services.

The challenge of how best to use ICT to empower communities and reduce poverty is still an area which needs further research; nevertheless, the debate on the utility of ICT in developing countries has largely been won [3, 38, 40]. In Africa, the public, governments and the donor community see ICT as a powerful tool in poverty reduction. Although the link between economic growth and ICT has been well established [24, 28], the exact processes of how ICT can be used for poverty reduction in developing countries need exploration and are open to challenge [26]. ICT as enablers in the development process and in poverty reduction can be envisaged using two approaches - ICT as a tool to promote economic growth (ICT-driven approach) or ICT used in support of development. In the ICT-driven approach, often underpinned by the assumption that better information improves how economic resources are allocated, one tries to empower the rural and urban poor by intervening to correct issues such as scarce, poor, inefficient, and untimely information by providing village knowledge centers. In this approach ICT can also be used to enhance health, education, social capital, etc. The other approach of using ICT in support of development first identifies the development goal (e.g., health care provision, increased agricultural yield, etc.), works out what the ICT needs of the target group are and then looks at how ICT and other media can play a role in providing and easing channels of communication. In using ICT to support development, the role of the poor in the identification of their information needs is greatly stressed [20].

Many international financial institutions (IFI) have issued reports on the economic arguments for ICT investments in developing countries and many recent reports discuss the distinct role ICT can play in bridging the information and knowledge gap for the poor [32].

This chapter explores the literature in areas such as ICT, socio-economic development, poverty reduction and the role of universities in knowledge creation and dissemination before taking a look at a university intervention in ICT for development in a small rural community in Yola, Adamawa State in Northeastern 
Nigeria. This research aims to be a theoretical contribution and a description of the activities of the American University of Nigeria through its community engagement initiative, The African Center for ICT Innovation and Training, and a theoretical discussion of the approach used in this intervention.

\section{Methodology}

A combination of surveys, interviews and an ethnographic study were chosen as the most appropriate methodologies to better understand the role of the Center since this will allow us to use an in-depth analysis of the social processes and economic histories of the community. Research included surveys which were handed out at the end of training modules and semi-structured interviews. The authors decided to use the Center as an area of focus since this is clearly an intervention whose role could possibly be ascertained from surveys of beneficiaries, the types of courses taught and the services offered by the Center and the perceived utility of the new skills learnt. By living within the community in the last three years and teaching at the Center, the authors were also able to use ethnographic methods such as unstructured interviews, and purposive trans-walks [7] by visiting the Center at least once a week unannounced to observe and interact with community members using the facilities and ask questions such as the utility of the courses offered, benefits accruing to them as a result of the new ICT skills being learnt, and how the Center has impacted their lives, etc. The survey was filled out by about 60 participants, about $40 \%$ of the total number of people trained at the Center during its first year of operations. Some of the findings are discussed in the case study.

\section{The role of universities in economic development}

Universities have long been recognized as providers of basic scientific knowledge for industrial innovation through their research and related activities in the agricultural and manufacturing sectors [16, 17, 19, 37]. Neoclassical economic theory explained the productive performance and competitive advantages of firms largely in terms of relative resource endowments [18]. The role of knowledge and of institutions involved in the creation of knowledge was seen as exogenous, i.e. external to businesses, though not unimportant, to the production system [15]. Therefore, Gunasekara argues, knowledge creation, almost exclusively scientific in nature, and predominantly applying to agriculture, manufacturing and mining, was viewed similarly as an exogenous factor in a firm's production function. The development and diffusion of knowledge was viewed in linear terms, known as the science push model [37] in the sense that knowledge was created outside the production system, either in universities or the laboratories of large firms and then "pushed" out to industry for applied development and adoption [42]. The notion of university-industry linkage, whereby the two institutions jointly or cooperatively 
developed knowledge was weak, applying largely to the conduct of trials or other experiments by universities to prove concepts during research [37].

Many theories have been put forth regarding the role of universities in regional innovation systems. These theories have evolved in the last two decades from an approach which highlighted the importance of knowledge spillovers from the educational and research activities of universities in regional knowledge spaces, known as the innovation systems approach, to the development of a third role performed by universities in stimulating regional economic and social development [8, 11-14, 21].

The role of African universities in poverty alleviation and economic development has received additional attention in recent years as a result of success stories from India, Ireland and other economies that have managed to build human capital, especially in ICT areas, and have been able to attract companies and jobs thereby helping in the fight against poverty.

The first generation of post-independent African universities focused on nation building, with emphasis on providing functionaries for the civil service [2, 44]. African universities are now faced with new challenges and the need to be germane in dealing with issues such as globalization, meeting basic needs, and contributing to the transition towards sustainable development [35]. However, most universities have been saddled with dwindling budgets, massive increases in enrollment, lack of adequately trained professors, decaying infrastructure and have been unable to meet the new realities on the ground.

In the 1980's, African universities were criticized as being elitist centers of privilege, far removed from the development challenges facing the continent and not being actively involved in finding solutions [44]. Therefore, African universities have been trying to reinvent themselves by becoming more engaged with their host communities and countries. Many African governments faced with mounting debt repayment obligations, decaying infrastructure, stifling conditionalities under Structural Adjustment Programs, and meager resources to be distributed among mounting problems in agriculture, health, infrastructure, etc., agreed with donor advice to focus on universal primary education since investments in higher education without the corresponding improvements in African economies was leading to mass exodus of university graduates and academics (brain drain) to the developed world .

In response to these challenges, a number of African countries are exploring how universities could contribute directly to economic transformation through closer interactions with the private sector and government. Universities and other institutions of higher education, such as technical colleges, have been arguably the most under-utilized institutions in efforts to promote sustainable development [44]. Today, African universities are largely places to train people in areas that have little relevance to the acute developmental needs of the continent or to keep the youths from the streets and unemployment ranks for several years, instead of being the bastions for productive activities, scientific and technological innovation and in the forefront of the fight against poverty and underdevelopment. According 
to Zaglu, Sherrard \& Juma (2006) [44] African universities can contribute to economic revival and growth in their surrounding regions, especially if they are located in rural areas where they can act as economic stimuli, facilitate the development of business and industrial firms, conduct Research and Development $(R \& D)$, create their own spin-off firms (bookstores, retail outlets, etc.), be involved in capital formation projects, such as technology parks and business incubator facilities, and introduce entrepreneurial and leadership training in their curricula. Universities can also ensure that students and faculty are involved in generating, adapting and diffusing available technical knowledge to meet local community and business needs.

\section{ICT for poverty alleviation and development}

According to Urquhart, Liyanage, \& Kah (2007) [38], ICT projects aimed at reducing poverty have often used models based on providing access to new technology, new skills and better ICT infrastructure with the expectation that ICT will primarily stimulate economic growth and production efficiency. Communities with low income and impoverished economies are expected to benefit from such ICT interventions because a direct correlation is assumed between ICT intervention and poverty reduction. Such a supply push approach has distinct limitations, because they do not take into account the endogenous capacity building and absorptive capacity of the community's knowledge, as well as the process of social capital formation.

Despite the complexity and cost of ICT, their uses in developing countries have ramifications for knowledge, information access and the economic and social welfare of communities. A strong correlation exists between the access to education and knowledge and poverty indicators such as infant mortality, family size, and women's health [32,38]. Other studies have also established a close link between poverty and an information gap of the poor (see for example, [6, 22]). In this paper we look at an ICT intervention in Yola, Adamawa State, Nigeria.

\section{Why ICT interventions in Africa fail to have substantial developmental impact}

Delivering and maintaining ICT projects in impoverished or remote areas is a major challenge due to technical and operational reasons [9]. Even though studies have shown that the commitment to access information and the realization that ICT is an important input has been high among poor people [25], getting the desired impact from ICT interventions is very difficult. From a supplier point of view, poverty alleviation can also be achieved by wealth distribution, and creation of infrastructure that can be activated only by direct intervention of governments and donors. Therefore, good governance is an important input for poverty alleviation and ICT has a role to play by disseminating information in impoverished areas. 
ICT capacity building has been defined as the human capacity to utilize ICT. One problem for ICT interventions in developing countries is the lack of resident ICT skills and expertise, which may hinder sustained operation of implemented systems [1], and lack of information literacy hinders adoption [29]. As participants use ICT for development, they should become part of a process of building human and intellectual capital, which in turn should increase total social capital [3]. However, the lack of available avenues to stimulate and sustain social capital in networks and among people is one of the reasons why developing countries fail to fully exploit the existing global technologies [30, 4, 5, 29, 33]. According to Urquhart, Liyanage and Kah, it is therefore important to consider not only the lack of human capital, but also the fact that low absorptive capacity of individuals and organisations inhibits the use of ICT together with the weak social capital formation that acts as a barrier. Any definition of social capital will necessarily have limitations, as it encompasses complex social dynamics such as integration, sharing, relationship building, motivation, trust and commitment. Urquhart, Liyanage and Kah concluded that the weaker the social capital, the harder it is for knowledge and human capital to grow in a community, thereby perpetuating poverty.

In the next section we look at issues such as gender relations, access, prohibitive cost of ICT and how poverty impedes ICT adoption and diffusion.

\subsection{Gender relations and ICT in Africa}

The Centre in our case study is aware of the disadvantaged position and condition of women in much of Africa, which is why it has programs specifically targeting women. In recent years, people involved in development have argued that the education of girls is probably the most cost-effective development investment. Female education leads not just to better employment opportunities but to a better distribution of benefits within a family. It leads to improved child health, reduced fertility, and it improves agricultural productivity as women do most of the work in this sector. Even though the assertion that educating women is of the most cost-effective development investments and a key to poverty reduction is now widely accepted, some studies have found women still have little access to ICT. With the right enabling environment, ICT can provide a route for economic empowerment of women [23]. Khasiani [27] and Opoku-Mensah [34] both discuss women, ICT and governance issues and suggests that women lack the access to information compared to their male counterparts.

The Yola community, which is largely Muslim, practices purdah, a system of seclusion of women. In northern Nigeria, this practice is more prevalent. VerEecke in an ethnographic study of Muslim women traders looked at gender relations in Yola and argues that in Northern Nigeria, purdah (seclusion) exists as a viable institution in which married women, largely speaking, can only leave the house with due cause, such as to receive medical treatment, to attend marriages and funerals, to visit nearby relatives, or in recent years to go to one's place of 
work [36]. Women, in most instances, must seek their husbands' permission to leave the house. Violation of these regulations may result in such measures as the accusation of promiscuity by one's family or, in an extreme form, divorce. The women's modesty is further enhanced by the use of the veil, and in some instances by the use of escorts. In much of northern Nigeria, even at present, the purity of young Muslim girls is also preserved by early marriage which tends to preclude their continuation of school beyond the primary level. A few husbands may allow their wives to continue their education, at times to the university level. But they usually limit their wives' choices of work to those with minimal direct malefemale interaction, especially as schoolteachers and nurses. However, increasingly there has been a gradual change in such rigidities. At AUN, the female students can be seen with their tight jeans, yet a headscarf to cover their heads. Even in recent times, many women, including some of our students believe that it is not their duty to work; for their husbands are obligated under Islam to provide for them and their children. This phenomenon was observed by the authors at the American University of Sharjah in the United Arab Emirates where women made up sixty-five percent of university students but were not joining the workforce in large numbers after graduation.

Despite Muslim men's control over their wives' extradomestic activities, women are in many respects politically and economically autonomous and develop activities that enhance their income or status, and provide them with an investment towards their future [39].

The Center has been very popular with women in Yola, with more women registering for courses compared to men. Being conveniently located within the community, the Center is accessible to young and married women making it possibly more likely that husband and parents will support their women to attend courses. Safety is also a major concern in Nigeria, therefore having the Center located in the community means students and people from the community do not have to travel to urban centers in other states to get advanced ICT training.

\subsection{Lack of access, ownership and control as barriers to the adoption of ICT}

Accessing ICT is a major impediment for many people in Nigeria and Africa. According to the Country Partnership Strategy for The Federal Republic of Nigeria (2005 - 2009) [43], teledensity though low has increased from .4 percent in December 1999 to over 6.5 percent in December 2004. The regulatory framework is state-of-the art. The response of the private investors has been remarkable. Private investments rose from $\$ 50$ million at end-1999 to $\$ 5.4$ billion at end-2004, so that the sector is second only to oil in Foreign Direct Investment (FDI). This shows unequivocally that the private sector can play a positive role in the economy. The IFC largest investment in Nigeria is in telecommunications. The National Monopoly (NITEL) is being prepared for privatization now. Deregulation of the telecommunications sector has been very effective. 
According to the Economist Intelligence Unit (EIU) 2007 [10], Nigerians have been slow to embrace Internet technology, partly because of prohibitive local subscription charges and the poor state of the local fixed-line telephone system. However, despite the high costs the number of Internet users has risen rapidly in recent years; from under 300,000 in 2002 to around 2.5 million in 2005 and an estimated 3.5 billion by late 2006. This is reflected in the growth of Internet service providers. These have been licensed by the Nigerian Communications Commission (NCC) since January 1999; more than 100 have a basic license, although a large number of them are inactive. However, owing to the high costs and the problems associated with telephone lines, access to the Internet is mainly provided by Internet cafés (which tend to be expensive and offer slow connectivity in order to charge customers more), which are present in most urban centers. This situation of low access to ICT will hopefully improve with an Abu Dhabi's investment arm, Mubadala Development, recently completing a $\$ 400$ million payment for a unified telecom license in Nigeria to offer services, such as fixedline, voice, data services and establish an international gateway, areas previously restricted to the four existing GSM operators in the country. With the largest population in the region of about 140 million Nigeria has potential for significant growth.

Urquhart, Liyanage \& Kah argue having access to computers alone does not guarantee transformation of communities and the positive impact of ICT being felt. Computers are not provided just for their sake. The aim of ICT interventions is to create desired transformation by giving people in rural areas access to a computer and the skills to use it. According to Urquhart, Liyanage \& Kah, in some cases in Bangladesh, some villagers were quite fearful of trying out new technology and this was a barrier to use of the technology. For example, in one village where two computers were provided, the computers were kept at one of the villager's house for safe keeping instead of being used. Any attempt to move this computer to another location which is central for people to use or try out met with resistance from the person who took charge of the equipment. The fear was grounded on the belief that if people break it, who will repair it? Others are not ready to use it and if they do they have to pay a nominal amount to use it. As a result, inputs are rarely transformed into any usable outputs with tangible benefits. The presence of two computers in the village, however, is a symbolic social capital where villages felt that they were part of the rest of the world although there was no use out of the computers and information that it can deliver.

In their article, Urquhart, Liyanage \& Kah argue that the transformation process envisaged in ICT interventions is also difficult due to the general level of education, where ICT education stands worlds apart from actual level of understanding. Villages require the information to be unpacked and presented to them. They were very interested in relevant information such as how to improve agricultural productivity. Indeed in the same village people were enthusiastic about a bee keeping project to be organized by Swedish Bee Keepers association bringing wealth of knowledge and skills that can be put into practice immediately. 
Villagers view ICT as intangible knowledge and an asset that can be of utility mostly for those who have knowledge to use it. As a result, two computers purchased for the village were left covered with a cloth over it, and served as a status symbol that indicates that the village now has educated people who can even use computers.

In our study area, Yola, Adamawa State, it was mostly the elites and some professionals who had access to computers and the internet at home. Given the poor state of electricity supply with rationing still prevalent, computer use at home is still low.

\section{Case study}

\subsection{The study area}

Nigeria, Africa's most populous country, is composed of more than 250 ethnic groups. The following are the most populous and politically influential: Hausa and Fulani 29\%, Yoruba 21\%, Igbo (Ibo) 18\%, Ijaw 10\%, Kanuri 4\%, Ibibio 3.5\%, and Tiv $2.5 \%$. Nigeria is large, diverse and complex. Nigeria's constitutionally powerful executive is constrained by the complexity of Nigeria's political system and the importance of ensuring national unity in a country with around 200 ethnic groups, 500 indigenous languages and two major religions (Islam and Christianity). Unfortunately, these potential cleavages in Nigerian society can be used for political ends. While there are indications that communal conflicts have subsided somewhat in the last two years, Nigeria remains vulnerable to resurgences of conflict. The Niger Delta despite its rich oil fields is very poor, with some community members feeling disenfranchised and excluded from the prosperity gained from oil revenues.

Nigeria's economic performance has improved in recent years partly due to improvements under a new reform-minded administration. Nigeria's former military rulers failed to diversify the economy away from its overdependence on the capital-intensive oil sector, which provides $20 \%$ of GDP, $95 \%$ of foreign exchange earnings, and about $65 \%$ of budgetary revenues. The largely subsistence agricultural sector has failed to keep up with rapid population growth - Nigeria is Africa's most populous country - and the country, once a large net exporter of food, now must import food [10].

\subsection{Socio-economic activities in Yola, Adamawa State}

Yola, the study area, is located in Adamawa state in Northeastern Nigeria. As with much of northern Nigeria, commerce and business (and of course government and military work), and not industry, have become the most popular and profitable enterprises. Following independence and the designation of Yola as the capital of Gongola State and the consequent new prospects of employment, migrations to Yola have accelerated greatly. Various peoples, especially the 
Hausa, recently joined by Yoruba and Igbo from southern Nigeria, continue to dominate large- and small-scale trade industries in Yola as well as in many of its nearby towns, and finally, Hausa is beginning to replace Fulfulde as a lingua franca in many parts of the emirate [39].

As a result of the proselytizing mission of the Fulbe during the jihad, Adamawa and Yola have assumed a distinctively Muslim character. Christian missionaries were effective only in some rural areas, and only recently have some Christians migrated to the Fulbe towns. In the traditional part of Yola (Yola Town), one mainly finds Fulbe (those with pure Fulbe ancestry and those incorporated into the Fulbe identity), with non-Fulbe nowadays settling on the town's fringes. In the sabon gari (Jimeta), which was established early this century for "strangers," reside Fulbe, Hausa, and Kanuri Muslims, Igbo and Bachama Christians, and Batta, Kilba, Verre, and Yoruba, along with individuals from about twenty other minority ethnic groups whose members are either Christian or Muslim (VerEecke 1993).

Northern Nigeria, despite its political dominance of the country, currently lags behind the South in industrial development and Western education, so that this region's peoples, especially the poor, are among the most greatly affected. Northern peoples' sentiments of deprivation have been expressed, for instance, in local ethnic and religious antagonisms along with popular, at times destructive movements such as the Maitatsine riots in the early and mid-1980s [39, 41, 31].

\subsection{The activities of the African Center for ICT Innovation \& Training}

In December 2005, American University of Nigeria (formerly Abti-American University of Nigeria) was notified of its successful grant application for $\$ 100,000$ to build and run the African Center for ICT Innovation \& Training to The John D. and Catherine T. MacArthur Foundation (henceforth MacArthur). The Founder of the university donated a building to which the chair of the Investment and Fund Raising Committee of the Board of Trustees donated N2,000,000 (Naira) (approximately $\$ 15,384$ ) for renovations. The university, in turn, matched the renovation grant, and works on the Centre started in April 2006.

The Center's building is ideal in several respects. It is located adjacent to another university building near the campus and is situated close to the Yola business district. The proximity to the university building allows for the sharing of generators and diesel, water and sewage, and parking lots.

\subsubsection{Incubator \& techno-preneurship activities}

The Center's goals include facilitating the development of ICT skills competencies of AUN staff, especially local staff, requisite for the operational needs of the university to coordinate library, admissions, registration and financial services to students and other related tasks. Further, the Centre recognized the value of training a small cadre of very bright, technologically advanced students 
excelling in ICT courses at AUN as well as recent top graduates from neighboring local universities and the local community of Yola and Jimeta by providing mentoring by ICT faculty and assigning supervised locally relevant software development activities with the expectation of developing product and services into marketable and usable software products. It is also the Center's aim that some of the ideas generated by students and faculty can result in next generation of software and ICT service providers responding to the needs of the local community and Sub-Saharan Africa.

An additional goal of the Center is to help provide advanced software technologies, internet connectivity/access to the community and ICT to some very bright students who graduated from the local Universities but were unable to have access to ICT during their undergraduate programs and/or at their institutions. The Center quickly recognized that very bright young men and women were graduating from these institutions with degrees in computer science, IT and other related fields but without the expected competencies. This is due mainly to the lack of access to ICT resources and capacity in most local and public universities. Access to modern software, Internet connectivity, ICT infrastructure and adequate faculty with the appropriate training/education in ICT is a rarity in most of institutions thus affecting the quality and competence of graduates. The center is also an ICT resource center for the community and for small businesses. The Centre continues to encourage particularly women in the communities of Yola and Jimeta to be trained in various aspects of ICT.

The group of students selected to be part of the Techno-Preneurship teams were mobilized to plan and create a registration application program that was used for the September 2006 intake of 300 students. This software was again adopted for the January 2007 intake. The students continue to enhance the functionality of the system that is evolving to be an adaptable and sustainable ERP system for higher education institutions in developing countries that will not be able to afford the Banner Solutions and/or DataTel Solutions. The applications being developed by the student Techno-Preneurship teams are designed to evolve as professional programs similar to the Banner system that will be adopted by the university. In the interim, AUN is using one of these Beta versions developed by one of the teams as its interim registration and admission systems. This system has great potential and we are working to enhance the modules to include a financial and advising module as well as convert it to Oracle. It is our hope that the students will be able to refine the application and introduce it to local universities for use.

The success of the Center's initial activity was spun off in October 2006 into another group of students which has begun to organize admissions data as well as another group adopting a local health care clinic (MATCO Clinic) based in the Yola/Jimeta community introducing the use and adoption of ICT as well as to design and develop a health care information systems. This has now evolved to a prototype knowledge support system for health informatics being developed.

A substantial percentage of students in the Center are female, amongst our most promising students, and are local to the community. These students are provided 
with a modest assistantship funded through the grant. It is also planned that these students will be the first to graduate and will thus lead AUN's employment profile in the business world.

\subsubsection{Staff upgrading}

The center is positioned to be a hub for ICT professional development and to improve the competencies of AUN staff as well as the larger communities of Yola and Jimeta. The Center is providing opportunity and access to ICT competency for the poor. The Center offers various levels of ICT training from basic to advanced to professional certifications. Another aim of the Center is to extend "self-paced, positive computer access and experience to local staff to create expectations of success and reliable performance," consistent with the work ethic of American universities. To date, this has happened in two ways. First, local staff members were given the opportunity to purchase AUN laptops and desktops in a heavily subsidized program. Second, recognizing occupational gaps in English competency, especially writing and e-mail messaging, the university offered free of charge a 4-week workshop in basic writing in spring 2006 and another in fall 2006. The class work and homework require the use of computers, and staff was released from duty in order to attend the courses.

All of the laptops and desktops in the distribution program were purchased by local staff, and the enrollment and attendance in the writing courses reached the maximum with classes remaining filled throughout the duration.

Further training leading to ICDL certification (International Computer Driver's License) progressed with 15 AUN local staff performing a diverse administrative function across the University with very minimum ICT skills. All these staffs were trained by highly qualified AUN faculty and learning is reinforced via self paced CBT's using SAM 2003 Training Assessment. These self paced CBT's are supported by the grant.

Furthermore, a group of 15 students from the Yola and Jimeta community were also trained along with the AUN University local staff. These are six week programs and all students that successfully completed the training will take the ICDL certification exams. The second batch of training for the local community commenced in May 2007. All the 30 participants currently undergoing training expressed interest to continue in the next level courses. The Center also fitted the infrastructure for the CISCO Academy and trained fifteen (15) community members for six weeks for the CCNA in May 2007. The center is also scheduled to offer short term training courses in Java and Web development.

\subsubsection{Industry-university engagement}

Selected students in the incubator worked on a prototype of "Knowledge Support Systems for Health Informatics" and this work continued through the summer of 2007 and is expected to be an application to be utilized by Health clinics in rural areas in Yola and Jimeta. Under the supervision of faculty, students 
were able to test these ideas developed in the Center and apply them to the needs of Yola and Jimeta rural communities.

The student activities also resulted in a Terms of Reference (TOR) and a Memorandum of Understanding (MOU) from The International Food Policy Research Institute (IFPRI) for collaboration and partnership with the Center to work with the Center's faculty associates and students to develop a Regional Strategic Analysis and Knowledge Support System (ReSAKSS) ICT Environment. A key element of the knowledge systems management component is the establishment of a ReSAKSS ICT and interactive website environment (RIE) to enable ready access to tools and information, promote mutual learning and peer-review, and facilitate dialogue on future priorities:

- Guiding the design and establishment of preliminary websites;

- Investigating and developing a comprehensive RIE;

- Coordination across nodes and select partners;

- Training and outreach for assessing and using the RIE resources.

Faculty Associates and students expect to commence work on these activities during summer 2008. Preliminary discussions and collaboration talks and project planning are taking place.

The Center also developed a program for "Women in ITC". This is an effort to increase the number of women at AUN studying and developing competences in computing as well as retention strategies for women enrolled in computing related programs. Several women from the community are undergoing training and mentorship at the Center. The center is contributing in the empowerment of women in the community via ICT competence and capacity development.

The center is also offering numerous IT industry certification programs such as Cisco, Microsoft, Oracle, IBM as well as programming (Java, C++, C\#\#, Java script, PHP, ASP) Linux and Open Source Technologies and Unix. This is accomplished by housing a Cisco Regional Networking Academy; an Oracle Academic Alliance, a Microsoft Academic Alliance as well as an Open Source (Linux) and Unix Lab. This is progressing well with the establishment of the Cisco Academy and the CCNA certification.

\subsubsection{The center's role in community engagement}

The importance in developing a culture of "Techno-Preneurship" via the Center's Tech incubator as a mechanism to develop the next generation of business of IT companies as well as IT leaders in Nigeria and Sub-Saharan Africa is demonstrated via the current teams of students tasked with various real life applications development, including an health informatics system for the community and the partnership and collaboration to develop a Knowledge Support System for the IFPIRI, an international organisation based in Washington.

The Center, through applied research on ICT development and poverty reduction, tries to disseminate and/or share knowledge and results relevant to policy makers as it relates to their efforts in developing and adopting ICT to 
improve government and private sector processes. This is done via numerous publications on peer reviewed journals and presentations and/or publications to peer reviewed conference proceedings.

Through the Center the next generation of competent skilled IT labor force can be developed to avail themselves to compete for the million dollar software and IT outsourcing global market. This can have very positive economic effects. This is being demonstrated through the ongoing training activities of the Center for different levels of ICT training.

The first phase entailed the development of a lab at the Center to house the Cisco Networking Academy program at AUN-SITC providing students with a skills-based career path on the information technology industry. This has been completed. The second phase entailed development of the Labs for the other areas of Information Technology such as an Oracle Lab, Linux and Unix Lab and Microsoft Lab to facilitate the requirements for their certification programs.

\subsection{Case study findings and discussion of the Center's impact}

The impact of the Center on the communities of Yola and Jimeta is an ongoing study. On March 6, 2008, the Center held its first formal graduation ceremony in which 62 participants attended to receive their training certificates. In total more than 102 participants have gone through the Center for training. Some of the observable impacts are:

- Students hands-on learning experience equipping them with applied skill sets in different competencies in ICT;

- Faculty's ability to adopt and utilize ICT in their teaching in order to facilitate learning by enhancing the mode of delivery;

- In the case of staff of the university, the Center has greatly helped to enhance their skill sets and allow them to become more efficient and productive in the performance of their daily tasks;

- More than 20 participants from the State government of Adamawa have been trained at the Center. Many of these civil servants are at mid-career levels and have greatly appreciated the opportunity offered by the Center and have indicated that they are more productive at work due to the skills they have learnt. In addition, having these computer skills make them more marketable, and;

- An environment and training for internationally recognized industry certification in different areas in ICT, for example Cisco, MSCE, Oracle, DB2, Linux, Unix, Programming skills in Java, C++, C\#\#, PHP, Java scripts etc, as well as web technologies and development skills.

\section{Conclusion}

The Yola community is currently engaged in the activities of the Center mainly through the numerous trainings offered on ICT skills. Without the Center there 
was little hope of enhancing the community's skill sets and enabling the community to benefit from being part of the digital world. The women members of the community currently in various levels of ICT training had little hope of much ICT training being in a rural community like Yola. The Yola and Jimeta communities are very satisfied and encouraged by the activities of the Center and its interventions to help bridge the digital divide and empower women in the community with appropriate ICT skills.

An additional group that is benefiting from the Center is students who graduated from local universities such as the Federal University of Technology (FUTI) but were unable to have access to ICT during their undergraduate programs and/or at their institutions. The Center quickly recognized that very bright young men and women were graduating from public and substandard private universities, colleges and institutions with degrees and diplomas in computer science, IT and other related fields but without the expected ICT competencies. This is due mainly to the lack of access to ICT resources and capacity in most local and public universities.

\section{References}

[1] Adam, M.S. \& Myers, M.D. (2003). Have you got anything to declare? Neocolonialism, information systems, and the imposition of customs and duties in a third world country, in M. Korpela, R. Montealegre and A. Poulymenakou (Eds.) Organisational information systems in the context of globalization. Dordrecht: Kluwer Academic Publishers.

[2] Amonoo-Neizer, E.H. (1998). Universities in Africa: The need for adaptation, transformation, reformation and revitalization. Higher Education Policy, 11, 301309.

[3] Avgerou, C. (2001). The significance of context in information systems and organisational change. Information Systems Journal, 11(1), 43-63.

[4] Bhatnagar, S. (2000). Social implications of information and communication technology in developing countries: lessons from Asian success stories, Electronic Journal on Information Systems in Developing Countries 1(4): 19.

[5] Braa, J., Macome, E., Mavimbe, J.C., Nhampossa, J.L., Costa, J.L., Jose', B., Manave, A. \& Sito'i, A. (2001). A study of the actual and potential usage of information and communication technology at district and provincial levels in Mozambique with a focus on the health sector, Electronic Journal on Information Systems in Developing Countries 5(2): 1-29.

[6] Burch, J. \& Grudnitski, G. (1986). Information systems: Theory and practice, $\left(4^{\text {th }}\right.$ ed.). New York: Wiley.

[7] Chambers, R. (1997). Whose reality counts: putting the first last. London: Intermediate Technology.

[8] Chatterton, P. \& Goddard, J. (2000). The response of higher education institutions to regional needs. European Journal of Education, 35(4), 475-496.

[9] Dymond, A. \& Oestmann, S. (2002). ICTs, poverty alleviation and universal access: Review of status and issues, ATPS Special Paper Series, (9), Nairobi: Kenya African Technology Policy Studies Network, http://www.atpsnet.org/.

[10] The Economist Intelligence Unit Limited (2007), Country Profile 2007, 20-21 at www.eiu.com. 
[11] Etzkowitz, H. \& Leydesdorff, L. (2000). The dynamics of innovation: From national systems and "mode 2" to a triple helix of university-industry-government relations. Research Policy, 29(2-3), 109-123.

[12] Etzkowitz, H., Webster, A., Gebhardt, C. and Terra, B. R. C. (2000). The future of the university and the university of the future: Evolution of ivory tower to entrepreneurial paradigm. Research Policy, 29(2), 313-330.

[13] Etzkowitz, H. (2002). Incubation of incubators: Innovation as a triple helix of university-industry-government networks. Science and Public Policy, 29(2), February, 115-128.

[14] Etzkowitz, H. (2002). MIT and the rise of entrepreneurial science. London: Routledge.

[15] Freeman, C. (1995). The national system of innovation in historical perspective. Cambridge Journal of Economics, 19, 5-24.

[16] Gunasekara, C. (2006). The generative and developmental roles of universities in regional innovation systems. Science and Public Policy, 33(2), 137-150.

[17] Guston, D. H. (2000). Retiring the social contract for science. Issues in Science and Technology, 16(4), 32-36.

[18] Hall, P. (1994). Innovation, economics and evolution. New York: Harvester Sheaf.

[19] Hart, D. M. (1988). Forged consensus: Science, technology and economic policy in the United States, 1921-1953. Princeton: Princeton University Press.

[20] Heeks, R. (2002). I-development not e-development: Special issue on ICTS and development. Journal of International Development, 14(1), 1-12.

[21] Holland, B. A. (1999). From murky to meaningful: the role of mission in institutional change. In R.G. Bringle, R. Games, \& E. A. Malloy (Eds.), Colleges and universities as citizens (pp. 48-73). Boston: Allyn \& Bacon.

[22] Humphrey, J. (2006). Prospects and challenges for growth and poverty reduction in Asia, Development Policy Review, 24(s1), s29-s49.

[23] Huyer, S. \& Mitter, S. (2003). ICTs, globalisation and poverty reduction: gender dimensions of the knowledge society part I, poverty reduction, gender equality and the knowledge society: digital exclusion or digital opportunity? Accessed on 9th August 2006 from http://gab.wigsat.org/partI.pdf.

[24] Jalava, I. \& Pohjola, M. (2002). Economic growth in the new economy: Evidence from advanced economies. Information Economics and Policy, 14(2), 189-210.

[25] Kayani, R. \& Dymond, A. (1997). Options for rural telecommunications development, World Bank Technical Paper, (359) http://www.inteleconresearch.com/pages/wbank.html.

[26] Kenny, C. (2002). Information and communication technologies for direct poverty alleviation: costs and benefits. Development Policy Review, 20, 141-157.

[27] Khasiani, S.A. (2000). Enhancing women's participation in governance: The case of Kakamega and Makueni districts, Kenya, in E.M. Rathgeber and E.O. Adera (Eds.) Gender and the Information Revolution in Africa, Ottawa: International Development Research Centre (IDRC), Chapter 8. http://www.idrc.ca/books/focus/903/11chp08.html.

[28] Kraemer, K.L. \& Dedrick, J. (2001). Information technology and productivity: results and policy implications of cross-country studies. In Pohjola, M. (Ed), Information technology, productivity, and economic growth, (pp. 257-279). Oxford: Oxford University Press.

[29] Lee, J. (2001). Education for technology readiness: prospects for developing countries, Journal of Human Development, 2(1): 115-151.

[30] Lim, E. (1999). Human resource development for the information society, Asian Libraries 8(5): 143-161. 
[31] Lubeck. P. (1986). Islam and urban labor in Northern Nigeria: the making of a Muslim working class. Cambridge: Cambridge University Press.

[32] Marker, P., McNamara K., \& Wallace L. (2002). The significance of information and communication technologies for reducing poverty. Report of the UK Department for International Development, 2002, retrieved from http://www.dfid.gov.uk/pubs/files/ictpoverty.pdf. Accessed 3 May 2006.

[33] Okunoye, A. (2003). Organisational information technology infrastructure in developing countries: A comparative analysis of national vs. international research organisations in two Sub-Saharan African countries, Journal of Information Technology Cases and Applications, 5(2):8-26.

[34] Opoku-Mensah, A. (2000). ICTs as tools of democratization: African women speak out, in E.M. Rathgeber and E.O. Adera (Eds.) Gender and the Information Revolution in Africa, Ottawa: International Development Research Centre (IDRC), Chapter 7, retrieved from http://www.idrc.ca/books/focus/903/10-chp07.html.

[35] Oyelaran-Oyeyinka, B. \& Barclay, L. (2004). Human capital and systems of innovation in African development. African Development Review, 16(1), 115-138.

[36] Pitten, R. (1987). Documentation of women's work in Nigeria: problems and solutions in sex roles. In C. Oppong, (Ed.), Population and development in West Africa, (pp. 25-44). London: James Currey.

[37] Smith, B. L. R. (1990). American science policy since World War II. Washington, DC: The Brookings Institution.

[38] Urquhart, C., Liyanage, S., \& Kah, M. (2007). ICTs and poverty reduction: a social capital and knowledge perspective. Journal of Information Technology.

[39] VerEecke, C. (1993). Muslim women traders of northern Nigeria: Perspectives from the City of Yola, Ethnology, 32(3), 217-236.

[40] Walsham, G., Sahay, S., \& Robey, D. (2004). MIS Quarterly call for papers: Special issue on information systems and developing countries. www.misq.org.

[41] Watts, M. (1985). Silent violence: food, famine, and peasantry in Northern Nigeria. Berkeley: University of California Press.

[42] Webster, A. (1999). Technologies in transition, policies in transition: Foresight in the risk society. Technovation, 19, 413-421.

[43 The World Bank Group \& Department for International Development (2005). Country partnership strategy for The Federal Republic of Nigeria (2005 - 2009).

[44] Zaglul, J., Sherrard, D., \& Juma, C. (2006). Higher education in economic transformation. International Journal of Technology and Globalisation, 2.3/4: 241251. 